Preife der vorberridenden Samenforten, wie fie auz bem Samenmagajin zu Darmftabt an bie Bemeinden verabfolgt wurben, incl. Tranşport, Gmballage u. f. w. (fr. per Bollpfuns.)

\begin{tabular}{|c|c|c|c|c|c|c|c|}
\hline Safre & fitefern & Frichten & \&ätchen & uborn & Gfdhen & şainbutien & Shwarjerlen \\
\hline 1861 & 30 & 9 & 14 & 4 & 3 & 4 & 10 \\
\hline 1862 & 54 & 15 & 15 & - & 6 & 6 & 15 \\
\hline 1863 & 54 & 12 & 24 & 6 & 6 & 6 & 12 \\
\hline 1864 & 42 & 12 & 36 & 12 & 6 & 6 & 18 \\
\hline 1865 & 48 & 21 & 42 & 3 & 6 & 3 & 12 \\
\hline 1866 & 54 & 24 & 36 & 12 & 18 & - & 12 \\
\hline
\end{tabular}

Darmfiad im Mai 1866.

Braun.

\title{
2. 2Balditren.
}

Wobl in wenigen Gabren find unfere Forften De\& Flađilnndez wegen $\mathfrak{A b g a b e}$ von Strelt: Materintien fo jehr in $\mathfrak{A n}$ juruđ genom= men worden, als foldes feit ber geringen Strohernte Dez Jahreb 1865 Der zall iff. Bo nur auf Begen und $\mathfrak{B n h n e n , ~ a u f ~} \mathfrak{B l o ̈ \beta} \not e n$,

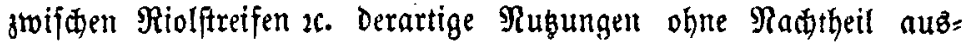
geübt werden tonnten, hat die Forftwirthidjaft Der Randwizthfdaft gern aus grober $\mathfrak{R o t h}$ gefolfen, und mit dem fo nothwendigen Streubedarfe gedient. Die im Sanzen vernbreidte Maffe hat eine

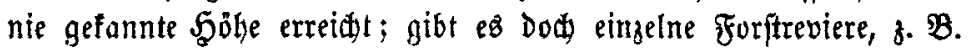

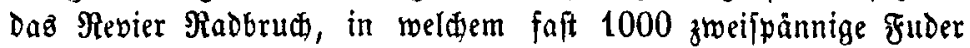

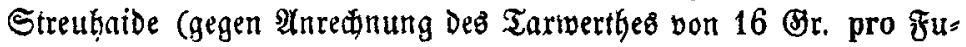
Der) abgegeben worden find.

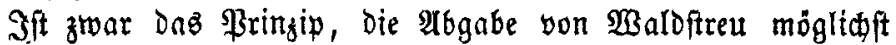

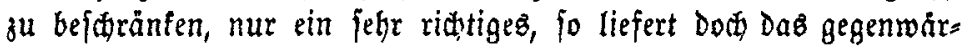
tige Jnhr Den Beweiz, Daj diefelbe bei Den now beftefenden land= wirthfdaftliden Einridtungen niđt immer zu entbehren ift.

Das Şauen Der Şaide mittelít Der fog. Imide Dürfte aber nie zu geftatten fein, vielmehn nur Das Mäken mit Der Şaibfituel - Der fog. Saatolehne - Damit die untere Deáe dem Boden er= balten bleibt. 


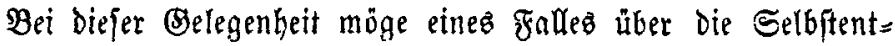
zündung bon Şaibe Errwätnung geidehen.

(Sin Ginwohner zu Borftel, $\mathfrak{A m}$ tz $\mathfrak{B i n f e n e r z , ~ h a t t e ~ i m ~ M o n a t e ~}$ December 1865 mehrere Fuder shoide nahe an jeinem $\mathfrak{B o h n h a u j e}$

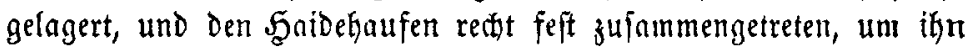

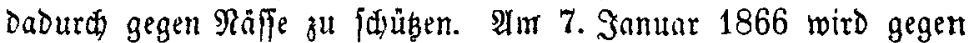

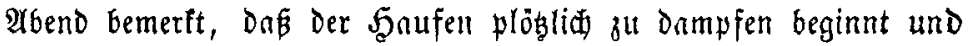

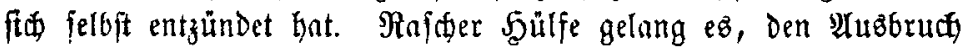
Des Feuers ju rerbindern, und das mit Stroh gededte Şaus yor Befahr zu befdüb̨rt.

5ุa bi

Sdjüttemamh,

Rönigl. Şannov. Dberförfter.

\section{Zualabar.}

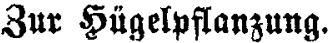

Der urjprủngliche 3wect Der Şügelpflanzung war, nuf nafjen und fauren Böben burch das 2ufwerfen bon (Erofäufchen Der \$flange

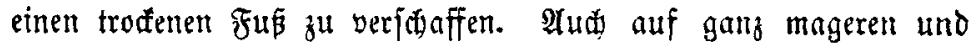
trofenen Böben hat fie günftige orrfolge gezeigt.

Dod) find eż aut nod andere Berfăltniffe, unter welden fie ifgre yolle Beadtung verdient.

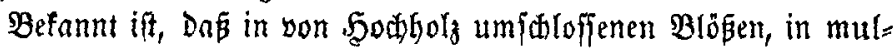
Denförmigen, falten $\mathfrak{B e r t i e f u n g e n ~ u n d ~ f e u d t e n ~ T h a ̈ l e r n ~ e i n e ~ R u l t u r ~}$ okne Schubeftand fidwer fortzubringen ift, weil fie von Spät= oder

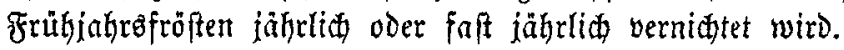

Dem Berfafjer find $\mathfrak{B e r f a ́ d t n i f f e ~ b e f a n n t , ~ w o ~ m a n ~ f i d ~ ( d i o n ~}$ 40 und mehr Gafre bemüht hat, Derartige Stellen aufauforften. Birfen, Şainbutđen, Fordien, Rärdien atles unterlag Dem Froft,

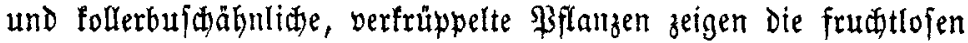
Bemühungen deg Forftmamng an.

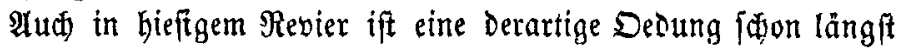
Begenftand forftlider Beratbung gewejen. 